\title{
QUU
}

\section{ESTUDO TEÓRICO DA 2,4-DINITRODIFENILAMINA ATRAVÉS DE MÉTODOS BASEADOS NA TD-DFT}

BORGES, J. M. G. (IFRN); LEAL, R. C. (IFRN)

Palavras Chave: 2,4-dinitrodifenilamina, efeito do solvente, DFT.

\section{INTRODUÇÃO}

A 2,4-dinitrodifenilamina, Figura 1, é um composto formado pelo processo de degradação de difenilamina, bastante utilizado como estabilizador na produção de explosivos. Pode atuar como um quimiossensor aniônico em solução, justamente por apresentar características especiais. ${ }^{1}$

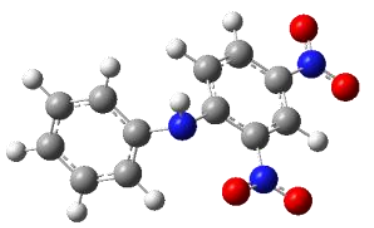

Figura 1: Geometria da 2,4-dinitrodifenilamina.

O presente trabalho tem como objetivo descrever, através de cálculos teóricos baseados na TD-DFT, o comportamento óptico da espécie 2,4-dinitrodifenilamina [1] e sua forma aniônica análoga [2].

METODOLOGIA

Todos os cálculos foram realizados com o software Gaussian $09 \mathrm{~W}^{2}$ As geometrias de equilíbrio foram obtidas, no vácuo, com funcional híbrido B3LYP e conjunto de base $6-31+G(d)$. Após as otimizações foram realizados cálculos TD-DFT (Time Dependent - Density Functional Theory) no vácuo e DMSO utilizando o modelo de solvatação implícito CPCM, variando o funcional com o mesmo conjunto de funções de base. Utilizou-se o valor default para o parâmetro largura à meia altura das bandas de absorção (FWHM) na obtenção de todos os espectros.

\section{RESULTADOS E DISCUSSÕES}

Os valores dos máximos de absorção são comparados entre si e com as informações experimentais, Tabela 1. Os aspectos qualitativos podem ser conferidos na Figura 2.

Os métodos CAM-B3LYP e $\omega B$ 97XD não diferem significativamente, veja o DAM (Desvio Absoluto Médio), apresentando portanto melhor desempenho entre os funcionais testados.
Tabela 1- $\lambda_{\text {máx }}(\mathrm{nm})$ para o 2,4-dinitrodifenilamina.

\begin{tabular}{ccccccc}
\hline $\begin{array}{c}\text { Modelo } \\
\text { Teórico }\end{array}$ & B3LYP & $\begin{array}{c}\text { M06- } \\
\text { 2X }\end{array}$ & $\begin{array}{c}\text { CAM- } \\
\text { B3LYP }\end{array}$ & PBE1 & WB97XD & DAM \\
\hline$[1]$ & 387 & 326 & 325 & 384 & 322 & \multirow{2}{*}{33,4} \\
{$[1]$} & {$[-18]$} & {$[43]$} & {$[44]$} & {$[-15]$} & {$[47]$} & \\
(DMSO) & 420 & 358 & 361 & 393 & 356 & 21,4 \\
& {$[-51]$} & {$[11]$} & {$[8]$} & {$[-24]$} & {$[13]$} & \\
{$[2]$} & $389 \mathrm{e}$ & $351 \mathrm{e}$ & $376 \mathrm{e}$ & $414 \mathrm{e}$ & $364 \mathrm{e}$ & 90,0 \\
& 403 & 367 & 584 & 738 & $560[67]$ & 90,0 \\
& {$[71]$} & {$[108]$} & {$[73]$} & {$[131]$} & $383 \mathrm{e}$ & \\
{$[2]$} & $420 \mathrm{e}$ & $367 \mathrm{e}$ & $364 \mathrm{e}$ & $390 \mathrm{e}$ & 380 & \\
(DMSO) & 770 & 435 & 539 & 710 & 440 & 90,2 \\
DAM & {$[144]$} & {$[66]$} & {$[56,5]$} & {$[129]$} & {$[55,5]$} & \\
\hline EXP. & 71 & 57 & 45,4 & 74,8 & 45,6 & $\#$ \\
\hline
\end{tabular}

*Exp. (DMSO): [1] $\lambda_{\text {máx. }}=369 \mathrm{~nm}$ e [2] $\lambda_{\text {máx. }}=436$ e $498 \mathrm{~nm}$

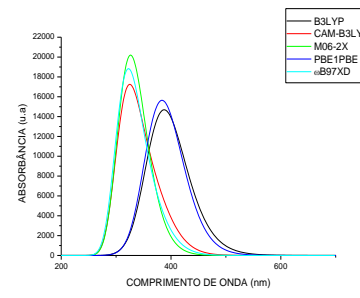

(a)

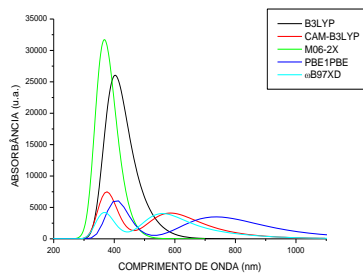

(c)

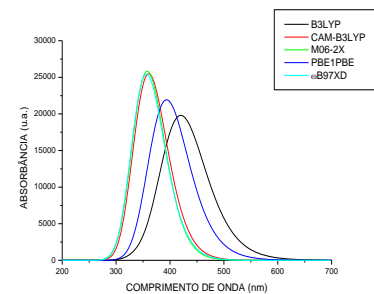

(b)

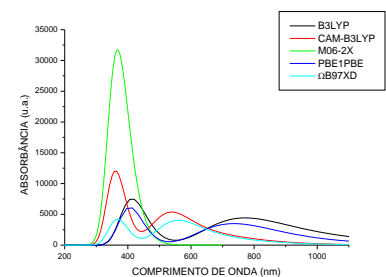

(d)
Figura 2- (a) molécula neutra no vácuo, (b) molécula neutra em DMSO, (c) molécula desprotonada no vácuo, (d) molécula desprotonada em DMSO.

\section{CONCLUSÃO}

Dentre os melhores funcionais testados, CAM-B3LYP e $\omega B$ 97XD, percebe-se que a inclusão do efeito de solvatação diminui bastante o erro, uma vez que aproxima-se ainda mais das condições realísticas.

\section{REFERÊNCIAS}

${ }^{1}$ MARINI, V. G.; Zimmermann, L. M.; Machado, V. G. Spectrochimica Acta Part A, 75, 2010, 799806.

2 <http://www.gaussian.com. Acessado em, agosto de 2016. 